\title{
Utilization of pain medications and its effect on quality of life, health care utilization and associated costs in individuals with chronic back pain
}

This article was published in the following Dove Medical Press journal: Journal of Pain Research

\section{Raj Desai \\ Young Rock Hong \\ Jinhai Huo}

Department of Health Services Research, Management and Policy, University of Florida, Gainesville, FL 32610, USA
Correspondence: Raj Desai

Department of Health Services Research, Management and Policy, University of Florida, 1225 Center Drive, Gainesville, FL 32610, USA

$\mathrm{Tel}+\mathrm{I} 6464363243$

Email raj.desai@ufl.edu
Purpose: Pain medications are widely prescribed to treat chronic back pain (CBP). However, the effect of using pain medications on individuals with CBP has received very little attention. Objective: The aim of this study was to determine the patterns of pharmacological treatment in the population with $\mathrm{CBP}$ and assess its impact on quality of life, health care utilization and associated costs in USA.

Patients and methods: Retrospective, cross-sectional data obtained from the Medical Expenditure Panel Survey (MEPS), from 2011 to 2015, were utilized for this study. Pharmacological treatment for CBP was categorized into three mutually exclusive categories: 1) opioids only, 2) nonsteroidal anti-inflammatory drugs (NSAIDs) only, 3) opioids and NSAIDs (combination). The effect of the use of these treatments was also evaluated.

Results: A total of 5,203 individuals with CBP were identified. Of these, 2,568 (49.4\%) utilized opioids only, 1,448 (27.8\%) utilized NSAIDs only and 1,187 (22.8\%) utilized both pain medications. Lower health-related quality-of-life scores on both the Short Form Health Survey-12 version 2 (SF-12v2) components (mental component summary score: 44.42 vs $46.67, P<0.001$; physical component summary score: 35.34 vs $40.11, P<0.001$ ) were observed for the opioid-only group compared to the NSAID-only group. In addition, individuals utilizing opioids only had greater utilization of inpatient services, office-based services, outpatient services and emergency room visits along with higher related health care costs.

Conclusion: Future researchers need to investigate the long-term risks and benefits of opioids, and policy makers should evaluate the prescribing guidelines to aim for a more patient-centered care. Keywords: opioids, NSAIDs, quality of life, health care resource utilization, cost

\section{Introduction}

Chronic back pain (CBP) is a very common health problem with a strong societal impact in USA. Approximately 16 million Americans experience at least one episode of CBP. ${ }^{1}$ According to the Centers for Disease Control and Prevention (CDC), it is the second leading cause of disability among adults in USA. ${ }^{2} \mathrm{CBP}$ also poses an economic burden to the society due to the loss of productivity (indirect cost) including increased risk of temporary work loss such as sick leave also known as absenteeism and/or reduced productivity while being present at work also known as presenteeism. ${ }^{3}$ This loss of productivity increases the treatment cost of CBP with the annual cost ranging from $\$ 12.2$ to $\$ 90.6$ billion in USA. ${ }^{4}$ 
The pharmacological treatment for CBP includes the use of nonsteroidal anti-inflammatory drugs (NSAIDs), acetaminophen, muscle relaxants as well as a short course of opioid pain medications. ${ }^{5,6}$ Many clinical trials have been conducted to determine the effectiveness of these pain medications. ${ }^{7-11}$ In the 2017 Strategies for Prescribing Analgesics Comparative Effectiveness (SPACE) trial, ${ }^{9}$ researchers randomly assigned patients seeking pain treatment to receive either opioids or NSAIDs such as acetaminophen or ibuprofen for 1 year at veterans affairs (VA) primary care clinics. This trial demonstrated that NSAIDs are equally effective as opioids to reduce pain. Another clinical trial compared efficacy and tolerability of two different combinations of opioids and NSAIDs (combination of hydrocodone and ibuprofen vs combination of oxycodone and acetaminophen), reporting that both the combinations are equally effective. ${ }^{11}$ However, two separate double-blind, double-dummy studies indicated that patients taking celecoxib (opioid) had a better response to pain compared to patients taking tramadol (NSAID) (study 1: 63\% vs 50\%, $P<0.001$; study $2: 64 \%$ vs $55 \%, P<0.008$, respectively). ${ }^{12}$

The current evidence about the effectiveness of opioids and NSAIDs on CBP management is conflicting. Furthermore, both opioids and NSAIDs are associated with side effects which may further complicate the treatment. ${ }^{13}$ These side effects negatively affect patients' quality of life and increase health resource utilization and costs associated with the illness. ${ }^{14-16}$ However, the association of the use of opioids and NSAIDs separately or in combination on the healthrelated quality of life (HRQoL) is not well understood. Data regarding the effect of these pharmacological treatments on health care utilization and cost in terms of inpatient visits, office-based visits, outpatient visits and emergency room (ER) visits are also scarce. Therefore, the purpose of this study was to fill these knowledge gaps by determining the association of three pharmacological treatments for CBP: 1) opioids only, 2) NSAIDs only and 3) combination of opioids and NSAIDs on HRQoL, health care utilization as well as health care costs.

\section{Patients and methods}

\section{Study design and data source}

We conducted a retrospective, cross-sectional analysis using 2011-2015 Medical Expenditure Panel Survey (MEPS) data. The MEPS was first conducted in 1996 and is now being carried out annually for civilian non-institutionalized Americans by Agency for Healthcare Research and Quality (AHRQ). ${ }^{17}$ The database consists of three major components from which health care data are drawn: 1) the MEPS Household
Component (MEPS-HC) which provides information about the respondent's demographics, socioeconomic characteristics, health status and access to care; 2) the MEPS Medical Provider Component (MEPS-MPC) which collects information regarding dates of visits, diagnoses leading to the visits and the utilization, payment and source of payment for the medical services and 3) The MEPS Insurance Component (MEPS-IC), in which the information regarding the type of insurance plans offered to their employees is collected from employers. In addition, information on premiums paid, any contributions made by employer or worker, eligibility requirements and benefit of the plan is also collected. ${ }^{17}$ The study was deemed exempt by the institutional review board of the University of Florida (IRB201801445) as MEPS is a deidentified and publicly available database that is intended for research purposes. Details regarding the data and a description of its survey design are provided elsewhere. ${ }^{17}$

\section{Study population}

The study population consisted of individuals aged 18 years and older diagnosed with CBP. These individuals were identified using the ICD, Ninth Revision, Clinical Modification (ICD-9-CM) codes: 720, 721, 722, 723, 724, $737,805,806,839,846$ and 847. The ICD-9-CM codes for identifying individuals with CBP have been validated in previous studies. ${ }^{18,19}$ In 2011-2015, there were 111,668 non-institutionalized civilian adults in MEPS data. Among these, 15,638 respondents with CBP were identified. Patients were excluded if opioids or NSAIDs were not used. The other exclusion criteria were as follows: aged $<18$ years, had missing values for physical component summary (PCS) and mental component summary (MCS) scores which are components of the Short Form Health Survey-12 version 2 $\left(\mathrm{SF}-12 \mathrm{v} 2^{\circledR}\right)$ and had duplicate records (complete inclusion and exclusion criteria are shown in Figure S1).

\section{Variables of interest Dependent variable HRQoL}

MEPS collects survey respondent's HRQoL information from the embedded SF-12v2. The SF-12v2 is a measure of HRQoL derived from the SF-36, which is a reliable and valid tool for measuring quality of life in clinical and general population in USA as well as in other countries..$^{20}$ The SF-12v2 measures eight domains of health including physical functioning, role physical, bodily pain, general health, vitality (energy/ fatigue), social functioning, role emotional and mental health (psychological distress and psychological well-being). ${ }^{20}$ The 
12 items consisting of the eight quality-of-life domains are calculated into two summary measures: PCS score and MCS score. The PCS score focuses on physical components such as general health, mobility, amount accomplished during physical activities, ability to climb stairs and work limitations resulting from physical problems or pain, whereas the MCS score focuses on mental components such as feelings of depression and anxiety, social activity, carelessness and impact of feelings on amount accomplished. ${ }^{20}$ The PCS and MCS scores range from 0 to 100 with higher scores representing better HRQoL. For the present study, we used the PCS and MCS scores to represent the physical and mental health components of HRQoL, respectively.

\section{Health care utilization and associated costs}

Health care resource utilization and associated costs were measured in terms of inpatient visits, outpatient visits, office-based visits and ER visits. In MEPS, health care cost information (payments in dollars) is collected for all persons for each medical event they experience in the year, including the amount from each payment source. In addition, expenditures in MEPS compose of direct payments for care provided during the year, including out-of-pocket payments and payments by private insurance, Medicaid, Medicare and other sources. ${ }^{17} \mathrm{We}$ also measured the total health care expenditure (inpatient cost + outpatient cost + office-based cost + ER cost) of each individual per calendar year. All expenditures in this study were adjusted to 2017 US dollars using consumer price indices for medical care. ${ }^{21}$

\section{Independent variable and other covariates}

The study cohort was grouped into three mutually exclusive groups based on the use of medication: 1) opioids only, 2) NSAIDs only and 3) combination of opioids and NSAIDs. Prescription fills for pain medications were identified using the Multum Lexicon ${ }^{\circledR}$ (a proprietary prescription drug database) codes "60" and "191" for opioids and "61" for NSAIDs. Other independent variables included demographic characteristics such as sex (male, female), race (whites, African Americans and others), age (grouped into 18-39, 40-64, 65 years and older), marital status (married, previously married and never married), education ( $0-12$ years, $>12$ years), poverty status (poor or near poor, middle income and high income), census region (northeast, midwest, south, west), health insurance (private, public and uninsured) and clinical characteristic such as the Charlson Comorbidity Index (CCI).

\section{Statistical analyses}

In the univariate analysis, we examined the difference in individuals' demographic, socioeconomic and clinical characteristics by the receipt of pain medication using chi-square tests. Multinomial logistic regression models were estimated to determine the association between the receipt of the type of pharmacological treatment for CBP and individuals' demographic, socioeconomic and clinical factors. In addition, we also performed multicollinearity assessment using variance inflation factor (VIF), tolerance value (TOL) and goodnessof-fit test to estimate and rule out any interactive effects of independent variables (multicollinearity) on the treatment of CBP. ANOVA test was used to compare the PCS and MCS scores between the three groups. Multiple linear regression was conducted to further examine the differences in these measures across demographic, socioeconomic and clinical factors. Negative binomial regression was used to determine differences in health care utilization, including inpatient hospitalizations, outpatient visits, office-based visits and ER visit. Selection of negative binomial regression model was made by model fit, which was determined by the Pearson's chi-square tests. We also compared the performance of the Poisson regression and negative binomial regression models and used negative binomial regression in this study as overdispersion was found to be an issue. Finally, health care costs among the three groups were estimated using generalized linear regression models with gamma distribution and log link. The complex survey design of MEPS was incorporated by using sample weights for stratum, cluster and individual people to produce national estimates. All probability values were considered significant at alpha level of 0.05. All statistical analyses were performed using SAS software (version 9.4; SAS Institute Inc., Cary, NC, USA).

\section{Results \\ Characteristics of individuals with CBP}

After applying the study's inclusion and exclusion criteria, a total of 5,203 individuals (weighted sample: 11,249,113) were included in our final sample. The majority of study cohort were female (57.4\%), individuals between the age of 40 and 64 years $(50.9 \%)$, white $(82.8 \%)$, married $(55 \%)$, had education $>12$ years $(86 \%)$, had a public health insurance coverage $(64.5 \%)$ and did not have any comorbidities $(55.1 \%$; Table S1).

\section{Treatment stratified by characteristics of CBP individuals}

Table 1 represents individuals' demographic, socioeconomic and clinical characteristics stratified by the use of pain 
Table I Type of pharmacological treatment among individuals with CBP stratified by demographic, socioeconomic and clinical characteristics, MEPS $201 \mathrm{I}-2015(\mathrm{~N}=5,203)$

\begin{tabular}{|c|c|c|c|c|}
\hline \multirow[t]{2}{*}{ Characteristics } & \multirow{2}{*}{ 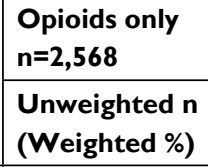 } & \multirow{2}{*}{$\begin{array}{l}\text { NSAIDs only } \\
n=1,448\end{array}$} & \multirow{2}{*}{\begin{tabular}{|l|}
$\begin{array}{l}\text { Opioids and NSAIDs } \\
\text { (combination) } n=I, 187\end{array}$ \\
$\begin{array}{l}\text { Unweighted } n \\
\text { (Weighted \%) }\end{array}$ \\
\end{tabular}} & \multirow[t]{2}{*}{$P$-value } \\
\hline & & & & \\
\hline \multicolumn{5}{|l|}{ Year } \\
\hline 2011 & $404(54.6)$ & $226(26.0)$ & $165(19.4)$ & 0.23 \\
\hline 2012 & $492(55.2)$ & $262(24.5)$ & $202(20.3)$ & \\
\hline 2013 & $45 \mathrm{I}(50.0)$ & $270(24.7)$ & $231(25.3)$ & \\
\hline 2014 & $527(54.3)$ & $286(25.4)$ & $233(20.3)$ & \\
\hline 2015 & $694(50.7)$ & $404(25.3)$ & $356(24.0)$ & \\
\hline \multicolumn{5}{|l|}{ Sex } \\
\hline Males & $1102(56.6)$ & $530(23.4)$ & $408(20.0)$ & $0.00^{\mathrm{a}}$ \\
\hline Females & 1466 (49.7) & $918(26.6)$ & $779(23.7)$ & \\
\hline \multicolumn{5}{|l|}{ Age } \\
\hline $18-39$ years & $584(46.6)$ & $447(29.1)$ & $348(24.3)$ & $<0.0001^{\mathrm{a}}$ \\
\hline $40-64$ years & $1301(50.5)$ & $735(25.9)$ & $642(23.6)$ & \\
\hline 65 years and above & $683(62.8)$ & $266(20.1)$ & $197(17.1)$ & \\
\hline \multicolumn{5}{|l|}{ Race } \\
\hline White & $1906(54.4)$ & $989(23.9)$ & $812(21.7)$ & $<\left.0.000\right|^{\mathrm{a}}$ \\
\hline African American & $490(46.1)$ & $327(30.4)$ & $271(23.5)$ & \\
\hline Other & $172(41.9)$ & $132(32.8)$ & $104(25.3)$ & \\
\hline \multicolumn{5}{|l|}{ Marital Status } \\
\hline Married & $1248(53.0)$ & $719(24.9)$ & $567(22.1)$ & $0.03^{\mathrm{a}}$ \\
\hline Previously Married & $838(55.0)$ & $380(22.9)$ & $361(22.1)$ & \\
\hline Never Married & $482(47.9)$ & $349(29.8)$ & $259(22.3)$ & \\
\hline \multicolumn{5}{|l|}{ Region } \\
\hline Northeast & $380(51.3)$ & $290(33.2)$ & $145(15.5)$ & $<\left.0.000\right|^{a}$ \\
\hline Midwest & $617(54.0)$ & $270(22.1)$ & $280(23.9)$ & \\
\hline South & $925(50.8)$ & $504(24.1)$ & $457(25.1)$ & \\
\hline West & $646(55.0)$ & $384(24.6)$ & $305(20.4)$ & \\
\hline \multicolumn{5}{|l|}{ Poverty Status } \\
\hline Poor & $1191(52.1)$ & $649(22.4)$ & $630(25.5)$ & $0.00^{\mathrm{a}}$ \\
\hline Middle Income & $68 I(5 I .9)$ & $418(27.2)$ & $289(20.9)$ & \\
\hline High Income & $696(53.8)$ & $38 I(26.5)$ & $268(19.7)$ & \\
\hline \multicolumn{5}{|l|}{ Education } \\
\hline $0-12$ years & $503(53.4)$ & $315(24.6)$ & $248(22.0)$ & 0.92 \\
\hline$>12$ years & $2065(52.5)$ & $1133(25.3)$ & $939(22.2)$ & \\
\hline \multicolumn{5}{|l|}{ Health Insurance } \\
\hline Public & $1414(52.6)$ & $830(26.6)$ & $610(20.8)$ & $0.00^{\mathrm{a}}$ \\
\hline Private & $928(53.3)$ & $452(21.0)$ & $474(25.7)$ & \\
\hline Uninsured & $226(50.3)$ & $166(28.7)$ & $103(21.0)$ & \\
\hline \multicolumn{5}{|c|}{ 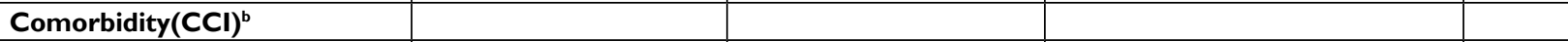 } \\
\hline 0 & $1322(49.9)$ & $926(28.9)$ & $645(21.2)$ & $<\left.0.000\right|^{\mathrm{a}}$ \\
\hline $\mathrm{I}-2$ & $79 \mid(53.4)$ & $392(22.6)$ & $383(24.0)$ & \\
\hline $2-4$ & $347(60.8)$ & $105(16.7)$ & $125(22.5)$ & \\
\hline$>4$ & $108(63.9)$ & $25(15.1)$ & $34(21.0)$ & \\
\hline
\end{tabular}

Notes: asignificant at $P<0.05$. ${ }^{b}$ Comorbidities were estimated using the $\mathrm{CCl}$.

Abbreviations: $\mathrm{CBP}$, chronic back pain; $\mathrm{CCl}$, Charlson Comorbidity Index; MEPS, Medical Expenditure Panel Survey.

medications. Of these individuals with CBP, 2,568 (49.4\%) received opioids only, 1,448 (27.8\%) received NSAIDs only and $1,187(22.8 \%)$ received both pain medications. The majority of the individuals who used opioids alone were males (56.6\%), 65 years and older $(62.8 \%)$, white (54.4\%), previously married (55\%), lived in the Western region of USA (55\%), had higher income (53.8\%), had private insurance (53.3\%) and had greater than four comorbidities (63.9\%). 


\section{Likelihood of receiving treatment for CBP}

The RR ratios (RRRs) and 95\% CIs for the likelihood of receiving NSAIDs only and a combination of opioids and NSAIDs with opioids only as the reference group are presented in Table 2. Females were more likely to receive
NSAIDs only (RRR: $1.31 ; 95 \%$ CI: $1.09-1.57$ ) and a combination of opioids and NSAIDs (RRR: 1.35; 95\% CI: 1.12-1.64) compared to males. The likelihood of using NSAIDs only was greater for African Americans (RRR: 1.44; 95\% CI: 1.15-1.82) and other races (RRR: 1.77; 95\% CI: 1.27-2.48) compared to whites. Similarly, the likelihood

Table 2 Factors associated with the likelihood of receiving NSAIDs only and combination of opioids and NSAIDs among individuals with CBP, MEPS 20II-20I5 (N=5,203)

\begin{tabular}{|c|c|c|c|c|c|c|}
\hline \multirow{3}{*}{$\begin{array}{l}\text { Characteristics } \\
\text { Year }\end{array}$} & \multicolumn{3}{|c|}{ NSAIDs only } & \multicolumn{3}{|c|}{ Opioids and NSAIDs (combination) } \\
\hline & \multirow[t]{2}{*}{ RRR $^{\mathbf{a}}$} & \multicolumn{2}{|c|}{$95 \% \mathrm{Cl}$} & \multirow[t]{2}{*}{$\mathbf{R R R}^{\mathbf{b}}$} & \multicolumn{2}{|c|}{$95 \% \mathrm{Cl}$} \\
\hline & & & & & & \\
\hline 2011 & $\mathrm{I}$ & & & $\mathrm{I}$ & & \\
\hline 2012 & 0.94 & 0.70 & 1.26 & 1.04 & 0.76 & 1.42 \\
\hline 2013 & 1.09 & 0.83 & 1.44 & $1.45^{c}$ & 1.06 & 2.00 \\
\hline 2014 & 1.00 & 0.75 & 1.34 & 1.05 & 0.78 & 1.40 \\
\hline 2015 & 1.10 & 0.82 & 1.47 & 1.34 & 0.99 & 1.82 \\
\hline \multicolumn{7}{|l|}{ Sex } \\
\hline \multicolumn{7}{|l|}{ Male } \\
\hline Female & $1.3 I^{\mathrm{c}}$ & 1.09 & 1.57 & 1.35 & 1.119 & 1.638 \\
\hline \multicolumn{7}{|l|}{ Age } \\
\hline $18-39$ years & I & & & I & & \\
\hline $40-64$ years & 0.94 & 0.74 & 1.20 & 0.89 & 0.67 & 1.17 \\
\hline$\geq 65$ & $0.70^{c}$ & 0.51 & 0.96 & 0.48 & 0.34 & 0.68 \\
\hline \multicolumn{7}{|l|}{ Race } \\
\hline White & $\mathrm{I}$ & & & $\mathrm{I}$ & & \\
\hline African American & $1.45^{c}$ & 1.15 & 1.82 & 1.10 & 0.88 & 1.36 \\
\hline Others & $1.78^{c}$ & 1.27 & 2.48 & 1.44 & 0.99 & 2.06 \\
\hline \multicolumn{7}{|l|}{ Marital status } \\
\hline Married & $\mathrm{I}$ & & & $\mathrm{I}$ & & \\
\hline Previously married & 0.94 & 0.75 & 1.18 & 0.86 & 0.70 & 1.05 \\
\hline Never married & 1.15 & 0.91 & 1.45 & 0.89 & 0.67 & 1.17 \\
\hline \multicolumn{7}{|l|}{ Region } \\
\hline Northeast & I & & & I & & \\
\hline Midwest & $0.66^{c}$ & 0.50 & 0.85 & $1.54^{c}$ & 1.18 & 1.99 \\
\hline South & $0.74^{c}$ & 0.58 & 0.94 & $1.72^{\mathrm{c}}$ & 1.32 & 2.22 \\
\hline West & $0.69^{c}$ & 0.53 & 0.90 & 1.27 & 0.97 & 1.67 \\
\hline \multicolumn{7}{|l|}{ Poverty status } \\
\hline Poor & $\mathrm{I}$ & & & I & & \\
\hline Middle income & 1.23 & 0.98 & 1.56 & 0.89 & 0.71 & 1.12 \\
\hline High income & 1.15 & 0.86 & 1.54 & 0.86 & 0.66 & 1.11 \\
\hline \multicolumn{7}{|l|}{ Education } \\
\hline $0-12$ years & $\mathrm{I}$ & & & 1 & & \\
\hline$>12$ years & 0.94 & 0.740 & 1.19 & 1.15 & 0.90 & 1.46 \\
\hline \multicolumn{7}{|l|}{ Health insurance } \\
\hline Public & $\mathrm{I}$ & & & I & & \\
\hline Private & 0.88 & 0.70 & 1.09 & $1.29^{c}$ & 1.03 & $1.6 \mathrm{I}$ \\
\hline Uninsured & 1.04 & 0.76 & 1.43 & 0.85 & 0.63 & 1.14 \\
\hline \multicolumn{7}{|c|}{ Comorbidity $(\mathrm{CCl})^{d}$} \\
\hline 0 & $\mathrm{I}$ & & & $\mathrm{I}$ & & \\
\hline $\mathrm{I}-2$ & 0.83 & 0.68 & 1.01 & 1.14 & 0.92 & $1.4 \mathrm{I}$ \\
\hline $3-4$ & $0.57^{c}$ & 0.41 & 0.79 & 1.00 & 0.73 & 1.37 \\
\hline$>4$ & $0.5 \mathrm{I}^{\mathrm{c}}$ & 0.29 & 0.89 & 0.94 & 0.57 & 1.56 \\
\hline
\end{tabular}

Notes: aRRR for receiving NSAIDs only compared to opioids only. ${ }^{\mathrm{b} R R R}$ for receiving a combination of opioids and NSAIDs compared to opioids only. ${ }^{\mathrm{c}}$ Significant at $P<0.05$. ${ }^{\mathrm{d}}$ Comorbidities were estimated using the $\mathrm{CCl}$.

Abbreviations: CBP, chronic back pain; $\mathrm{CCl}$, Charlson Comorbidity Index; MEPS, Medical Expenditure Panel Survey; RRR, RR ratio. 
of using a combination of opioids and NSAIDs was greater for African Americans (RRR: 1.10; 95\% CI: 0.88-1.36) and other races (RRR: 1.44; 95\% CI: 0.99-2.06), but the results were not statistically significant. CBP individuals aged 65 years and older were $30 \%$ less likely to utilize NSAIDs only (RRR:0.70; 95\% CI: 0.51-0.96) and 52\% less likely to utilize a combination of opioids and NSAIDs (RRR:0.48; 95\% CI: 0.34-0.68) compared to younger individuals (18-39 years). However, other factors such as marital status, health insurance, education, poverty status and comorbidity were not statistically significant.

\section{Comparison of HRQoL among different treatment groups}

CBP individuals utilizing NSAIDs only had higher mean PCS score compared to individuals utilizing opioids only and a combination of opioids and NSAIDs (40.11 vs 35.34 vs 34.76, respectively, $P<0.001)$. Similarly, individuals utilizing NSAIDs only also had a higher mean MCS score compared to the opioids-only group and combination group (46.67 vs 44.42 vs 44.37 , respectively, $P<0.001$; Figure 1 ). In the multiple linear regression models (Table 3 ), aging was found to be associated with lower physical health $(-6.39)$, but higher mental health scores (3.92). Individuals with middle and high income had statistically significant increased PCS and MCS scores compared to individuals with poor income. Individuals with private insurance had lower PCS and MCS scores compared to individuals having public insurance ( -4.29 and -2.45 , respectively). Moreover, increase in the number of comorbidities was associated with reduced PCS and MCS scores for the CBP population. All these differences were statistically significant $(P<0.0001)$.
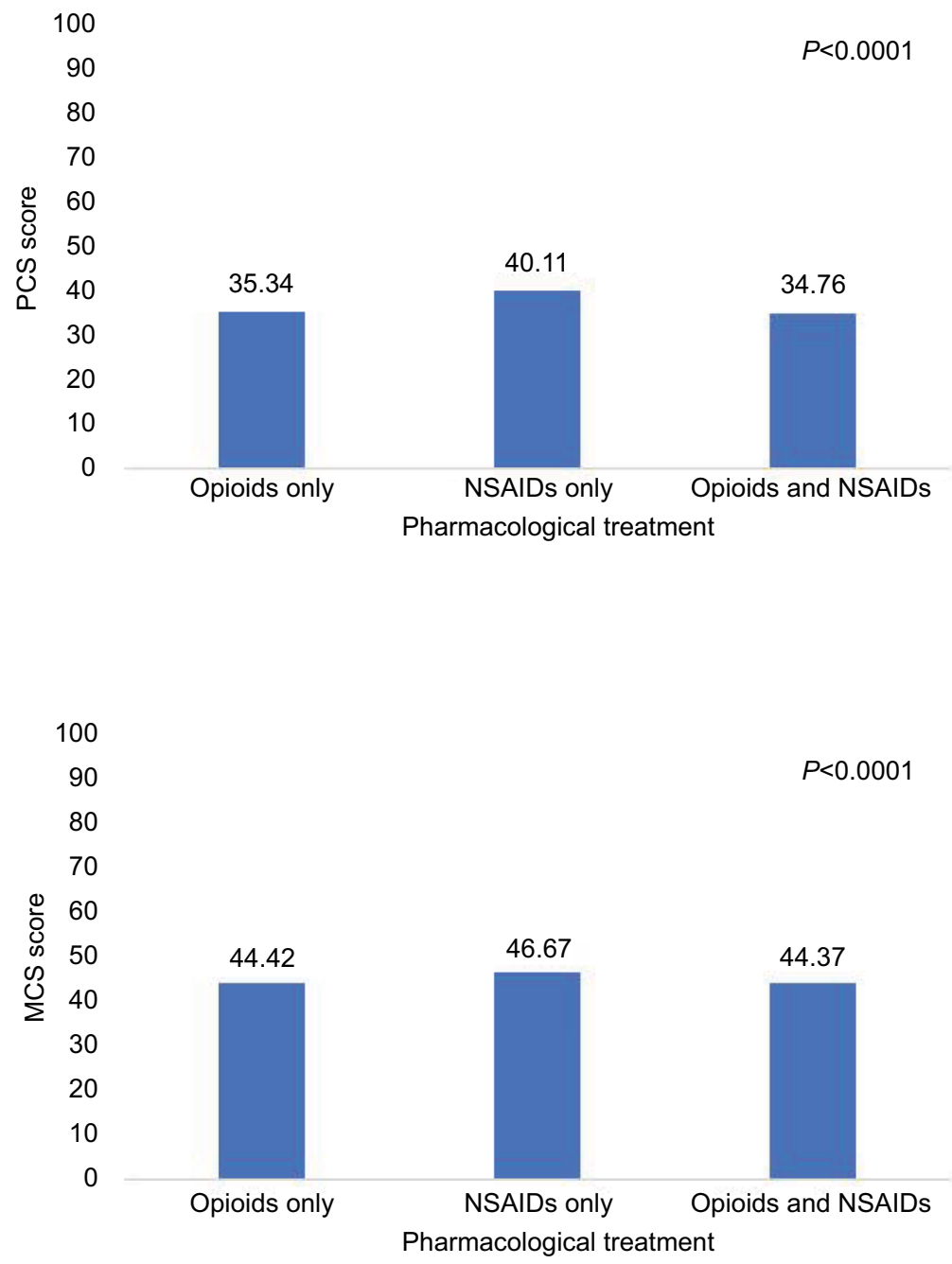

Figure I Comparison of HRQoL using SF-12v2 (PCS score and MCS score) between treatment groups: opioids only, NSAIDs only and combination of opioids and NSAIDs adjusted for all covariates.

Abbreviations: HRQoL, health-related quality of life; MCS, mental component summary; PCS, physical component summary; SF-12v2, Short Form Health Survey-12 version 2. 
Table 3 Multiple linear regression model for the comparison of PCS and MCS scores in individuals with CBP $(N=5,203)$

\begin{tabular}{|c|c|c|c|c|c|c|c|c|}
\hline \multirow{3}{*}{$\begin{array}{l}\text { Characteristics } \\
\text { Year }\end{array}$} & \multicolumn{4}{|l|}{ PCS } & \multicolumn{4}{|l|}{ MCS } \\
\hline & \multirow[t]{2}{*}{ Estimate } & \multicolumn{2}{|l|}{$95 \% \mathrm{Cl}$} & \multirow[t]{2}{*}{$P$-value } & Estimate & \multicolumn{2}{|c|}{$95 \% \mathrm{Cl}$} & \multirow[t]{2}{*}{$P$-value } \\
\hline & & & & & & & & \\
\hline 2011 & 0 (reference) & & & & & & & \\
\hline 2012 & -0.19 & -1.34 & 0.95 & 0.74 & -0.17 & -1.36 & 1.01 & 0.77 \\
\hline 2013 & -0.01 & -1.16 & 1.14 & 0.98 & 0.00 & -1.18 & 1.19 & 0.99 \\
\hline 2014 & 0.86 & -0.26 & 1.99 & 0.13 & 0.33 & -0.83 & 1.50 & 0.58 \\
\hline 2015 & -0.48 & -1.54 & 0.58 & 0.38 & 0.16 & -0.94 & 1.25 & 0.77 \\
\hline \multicolumn{9}{|l|}{ Group } \\
\hline Opioids only & 0 (reference) & & & & 0 (reference) & & & \\
\hline NSAIDs only & 4.74 & 3.94 & 5.54 & $<0.000 \mathrm{I}^{\mathrm{a}}$ & 2.26 & 1.44 & 3.08 & $<\left.0.000\right|^{\mathrm{a}}$ \\
\hline Opioids and NSAIDs & -0.60 & -1.44 & 0.25 & 0.1664 & -0.04 & -0.92 & 0.83 & 0.92 \\
\hline \multicolumn{9}{|l|}{ Sex } \\
\hline Male & 0 (reference) & & & & 0 (reference) & & & \\
\hline Female & -0.07 & -0.77 & 0.63 & 0.85 & -0.92 & -1.64 & -0.20 & $0.0 \mathrm{I}^{\mathrm{a}}$ \\
\hline \multicolumn{9}{|l|}{ Age } \\
\hline 18-39 years & 0 (reference) & & & & 0 (reference) & & & \\
\hline $40-64$ years & -6.05 & -6.91 & -5.18 & $<\left.0.000\right|^{a}$ & -0.74 & -1.64 & 0.15 & 0.10 \\
\hline$\geq 65$ & -6.39 & -7.50 & -5.28 & $<0.000 I^{a}$ & 3.92 & 2.78 & 5.07 & $<0.000 \mathrm{I}^{\mathrm{a}}$ \\
\hline \multicolumn{9}{|l|}{ Marital status } \\
\hline Married & 0 (reference) & & & & 0 (reference) & & & \\
\hline Previously married & 0.78 & -0.03 & 1.60 & 0.06 & -2.34 & -3.20 & -1.49 & $<\left.0.000\right|^{\mathrm{a}}$ \\
\hline Never married & 2.35 & 1.41 & 3.29 & $<0.000 \mathrm{I}^{\mathrm{a}}$ & -1.06 & -2.02 & -0.09 & $0.03^{\mathrm{a}}$ \\
\hline \multicolumn{9}{|l|}{ Region } \\
\hline Northeast & 0 (reference) & & & & 0 (reference) & & & \\
\hline Midwest & -0.87 & -1.97 & 0.23 & 0.12 & -0.85 & -1.99 & 0.28 & 0.14 \\
\hline South & -1.38 & -2.40 & -0.36 & $0.00^{\mathrm{a}}$ & -1.03 & -2.08 & 0.02 & 0.05 \\
\hline West & -0.35 & -1.42 & 0.72 & 0.52 & -1.39 & -2.49 & -0.28 & $0.0 \mathrm{I}^{\mathrm{a}}$ \\
\hline \multicolumn{9}{|l|}{ Poverty status } \\
\hline Poor & 0 (reference) & & & & 0 (reference) & & & \\
\hline Middle income & 2.63 & 1.75 & 3.52 & $<\left.0.000\right|^{a}$ & 2.30 & 1.38 & 3.22 & $<\left.0.000\right|^{\mathrm{a}}$ \\
\hline High income & 5.00 & 4.02 & 5.97 & $<0.000 \mathrm{I}^{\mathrm{a}}$ & 4.26 & 3.25 & 5.28 & $<\left.0.000\right|^{\mathrm{a}}$ \\
\hline \multicolumn{9}{|l|}{ Education } \\
\hline $0-12$ years & 0 (reference) & & & & 0 (reference) & & & \\
\hline$>12$ years & 0.47 & $-0.4 \mathrm{I}$ & 1.35 & 0.30 & 1.24 & 0.33 & 2.15 & $0.0 \mathrm{I}^{\mathrm{a}}$ \\
\hline \multicolumn{9}{|l|}{ Health insurance } \\
\hline Public & 0 (reference) & & & & 0 (reference) & & & \\
\hline Private & -4.29 & -5.15 & -3.43 & $<\left.0.000\right|^{a}$ & -2.45 & -3.35 & -1.55 & $<\left.0.000\right|^{\mathrm{a}}$ \\
\hline Uninsured & -1.30 & -2.55 & -0.06 & $0.04^{\mathrm{a}}$ & -1.43 & $-2.7 I$ & -0.14 & $0.03^{\mathrm{a}}$ \\
\hline \multicolumn{9}{|l|}{ Comorbidity $(\mathrm{CCl})^{\mathrm{b}}$} \\
\hline 0 & 0 (reference) & & & & 0 (reference) & & & \\
\hline $1-2$ & -4.78 & -5.56 & -3.99 & $<0.000 \mathrm{I}^{\mathrm{a}}$ & -1.97 & -2.77 & -1.16 & $<0.000 I^{\mathrm{a}}$ \\
\hline $3-4$ & -7.52 & -8.67 & -6.37 & $<0.000 \mathrm{I}^{\mathrm{a}}$ & -3.67 & -4.85 & -2.49 & $<\left.0.000\right|^{\mathrm{a}}$ \\
\hline$>4$ & -10.69 & -12.64 & -8.75 & $<\left.0.000\right|^{a}$ & -6.65 & -8.65 & -4.64 & $<\left.0.000\right|^{\mathrm{a}}$ \\
\hline
\end{tabular}

Notes: aSignificant at $P<0.05$. ${ }^{\circ}$ Comorbidities were estimated using the $\mathrm{CCl}$.

Abbreviations: $\mathrm{CBP}$, chronic back pain; $\mathrm{CCl}$, Charlson Comorbidity Index; MCS, mental component summary; PCS, physical component summary.

\section{Comparison of health care utilization among different treatment groups}

The mean differences in the health service utilization among the three treatment groups are summarized in Table S2: CBP individuals utilizing opioids only had significantly greater utilization of inpatient visits (mean number of visits per individual: 0.29 vs 0.09 ), outpatient visits (mean number of visits per individual: 1.39 vs 0.80 ), office-based visits (mean number of visits per individual: 14.46 vs 10.18 ) and ER visits (mean number of visits per individual: 0.60 vs 0.38 ) compared to NSAIDs only but lower number of outpatient (mean number of visits per individual: 1.39 vs 1.43), officebased (mean number of visits per individual: 14.46 vs 14.98 ) and ER visits (mean number of visits per individual: $0.60 \mathrm{vs}$ 
0.86) compared to the individuals utilizing a combination of opioids and NSAIDs. All results were statistically significant $(P<0.0001)$.

\section{Comparison of health care costs among different treatment groups}

After adjusting for the relevant covariates, compared to the individuals utilizing opioids only and NSAIDs only, CBP individuals utilizing a combination of opioids and NSAIDs had higher mean outpatient cost ( $\$ 3,087$ vs $\$ 3,020$ vs $\$ 2,177$, respectively), office-based visit cost (\$3,083 vs $\$ 2,652$ vs $\$ 1,984$ ) and ER cost (\$2,168 vs $\$ 1,883$ vs $\$ 1,607$; Figure 2). Table S3 describes the incremental effects of total health care expenditures among the US adults diagnosed with CBP. After controlling for all covariates, individuals utilizing NSAIDs only had significantly lower expenditures compared to individuals utilizing opioids only $(-\$ 5,362,95 \% \mathrm{CI}$ : $-\$ 6,711$ to $-\$ 4,013, P<0.001)$. Females, being 65 years and older, white, having higher income, publicly insured and having greater than one comorbidities, were associated with significantly higher total health care expenditures.

\section{Discussion}

This study characterized and compared quality of life, health care resource utilization and costs between CBP individuals utilizing opioids only, NSAIDs only and combination therapy. Like previously published claims studies, this study also found that CBP individuals receiving opioids utilized significantly more health care resources, incurred more costs and had a lower quality of life than those receiving NSAIDs. These results highlight the need for health care providers to evaluate the treatment goal and assess whether individuals with CBP should continue receiving opioid therapy.

In spite of CDC's recently published guidelines for prescribing opioids recommending the use of non-opioid analgesics as the first-line therapy for chronic pain in the absence of cancer, palliative or terminal care, ${ }^{22}$ this study found that almost half of the individuals with CBP were prescribed opioids as the first-line therapy, a finding which is also consistent with a previous study. ${ }^{23} \mathrm{~A}$ higher proportion of males were utilizing opioids compared to females. These results were in contrast to studies conducted by Bawor et $\mathrm{al}^{24}$ and Manubay et al. ${ }^{25}$ It is believed that females experience greater clinical pain, suffer from greater psychiatric and physical comorbidities and are more sensitive to pain compared to males. ${ }^{26,27}$ In line with expectations, individuals in the age group of 65 years and older had a greater utilization of opioids compared to younger adults (20-39 years). This finding is consistent with other studies ${ }^{28,29}$ as chronic pain is common among older age groups. The greater use of opioids in elderly can be justified as opioids can help older adults treat debilitating pain that might otherwise leave them immobilized. ${ }^{30}$ It is also noteworthy that the white population had a higher utilization of opioids compared to other races. These findings were consistent with a study conducted by Chen et al. ${ }^{31}$ Higher opioid utilization in whites could be associated with the prevalence of mental health conditions such as depression, anxiety, Post traumatic stress disorder or substance abuse. ${ }^{32}$ In addition, patient, provider- or system-level factors could also have contributed to such overwhelming disparity.

Although the ultimate goal of using pain medications for the treatment of CBP is to ease the burden of pain and

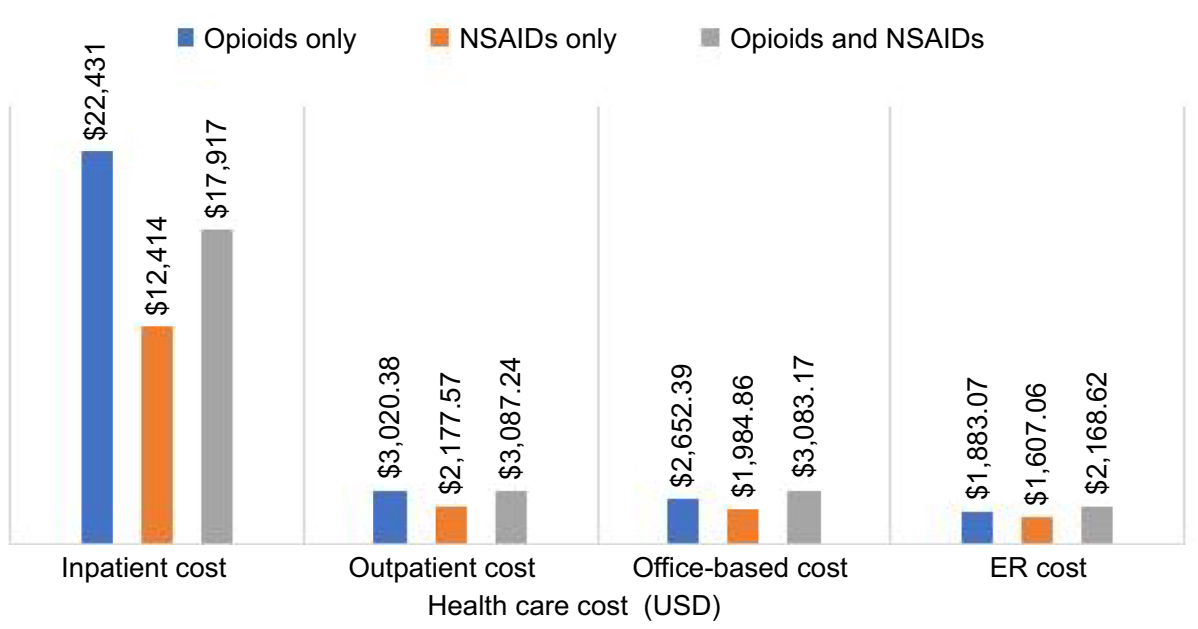

Figure 2 Comparison of mean adjusted cost between the three pharmacological treatment groups: opioids only, NSAIDs only and combination of opioids and NSAIDs adjusted for all covariates.

Abbreviation: ER, emergency room. 
hopefully improve quality of life, studies have demonstrated a negative association between opioid use and quality of life. ${ }^{3-36}$ A Danish epidemiological study by Eriksen et $\mathrm{al}^{33}$ evaluated the effects of the long-term ( $>6$ months) use of opioids in a sample of 16,684 individuals with chronic noncancer pain. They concluded that opioids had a negative influence on all of the items in the 36-Item Short Form Health Survey (SF-36) which used to score HRQoL. In our study, too, the use of opioids was associated with lower quality of life as evidenced by lesser scores in the opioid-only group compared to the NSAID-only group in both physical and mental components of the SF-12v2.

Although the use of opioids to manage pain continues in CBP individuals, their use eventually may have substantial consequences. There is evidence that opioids are associated with a range of side effects and potentially serious adverse events which could lead to greater utilization of health care resources.$^{37}$ In addition, prior studies have also demonstrated a significant association between the use of opioids and increase in the length of stay and 30-day readmission rates along with increase in cost of care. ${ }^{15,16,38}$ Indeed, our findings were in accord to the literature, as the use of opioids was associated with greater use of inpatient visits, outpatient visits, officebased visits and ER visits. Furthermore, individuals utilizing opioids also incurred greater cost of care in terms of inpatient visits, outpatient visits, ER visits and office-based visits.

The current study made unique contributions to the nascent literature on the treatment patterns among individuals with CBP. Findings from this study have clinical practice and policy implications. Our findings could encourage the health care providers to prescribe NSAIDs instead of opioids for CBP conditions as the utilization of opioids may increase the chances of chronic opioid use, lead to addiction and cause permanent disability along with increase in the health care utilization and cost of care. Moreover, this study suggests the need of preference-based treatments which could bring new perspectives to this field - a paradigm shift from disease-specific care to a more patient-centered care for CBP individuals.

\section{Study limitations}

Like any retrospective cross-sectional study, our research has several limitations. First, causal inferences may not be drawn. Second, individuals with CBP were identified using three-digit ICD-9 codes from MEPS which may have led to an underestimation of cases. Third, data on the use of medications were collected by interviewers, which may be prone to coding error and limit data accuracy. Fourth, MEPS does not include institutionalized individuals, which limits the generalizability of our study in this population. Fifth, we did not include out-of-pocket payments made for health insurance premiums in the calculation of health expenditures. Our analysis did not account for the health care provider characteristics as well as patient/provider preference for the treatment of CBP. Finally, in spite of accounting for costs associated with NSAIDs/opioids use, it is difficult to capture the expenditure associated with other potential costs for managing patient care in $\mathrm{CBP}$.

\section{Conclusion}

Our study findings indicated that almost half of the individuals suffering from CBP were utilizing only opioids which is concerning. In addition, the study suggests that although both the opioids and NSAIDs are recommended for chronic pain, the use of opioids was associated with greater health care utilization and cost in terms of inpatient visits, outpatient visits, office-based visits and ER visits. Future research is needed to compare the long-term risks and benefits associated with pain medications in those with CBP, which could inform the current prescription guidelines.

\section{Disclosure}

The authors report no conflicts of interest in this work.

\section{References}

1. Martin BI, Deyo RA, Mirza SK, et al. Expenditures and health status among adults with back and neck problems. JAMA. 2008;299(6):656-664.

2. CDC [homepage on the Internet]. Prevalence and Most Common Causes of Disability Among Adults - United States; 2005. Available from: https://www.cdc.gov/mmwr/preview/mmwrhtml/mm5816a2.htm. Accessed December 20, 2018.

3. Maetzel A, Li L. The economic burden of low back pain: a review of studies published between 1996 and 2001. Best Pract Res Clin Rheumatol. 2002;16(1):23-30.

4. Haldeman S, Dagenais S. A supermarket approach to the evidenceinformed management of chronic low back pain. Spine J. 2008;8(1):1-7.

5. Mayo Clinic [webpage on the Internet]. Back pain - Diagnosis and treatment - Mayo Clinic. Available from: https://www.mayoclinic. org/diseases-conditions/back-pain/diagnosis-treatment/drc-20369911. Accessed December 20, 2018.

6. Knezevic NN, Mandalia S, Raasch J, Knezevic I, Candido KD. Treatment of chronic low back pain - new approaches on the horizon. J Pain Res. 2017;10:1111-1123.

7. Pelletier JP, Martel-Pelletier J, Rannou F, Cooper C. Efficacy and safety of oral NSAIDs and analgesics in the management of osteoarthritis: evidence from real-life setting trials and surveys. Semin Arthritis Rheum. 2016;45(4 Suppl):S22-S27.

8. Carvalho C, Caetano JM, Cunha L, Rebouta P, Kaptchuk TJ, Kirsch I. Open-label placebo treatment in chronic low back pain: a randomized controlled trial. Pain. 2016;157(12):2766-2772.

9. Krebs EE, Gravely A, Nugent S, et al. Effect of opioid vs nonopioid medications on pain-related function in patients with chronic back pain or hip or knee osteoarthritis pain: the space randomized clinical trial JAMA. 2018;319(9):872-882. 
10. Cadavid-Puentes A. Comparison of the effectiveness of fentanyl versus morphine for severe postoperative pain management. A randomized, double blind, clinical trial. Colomb. J. Anesthesiol. 2017;45:100-107.

11. Palangio M, Morris E, Doyle RT, Dornseif BE, Valente TJ. Combination hydrocodone and ibuprofen versus combination oxycodone and acetaminophen in the treatment of moderate or severe acute low back pain. Clin Ther. 2002;24(1):87-99.

12. O'Donnell JB, Ekman EF, Spalding WM, Bhadra P, McCabe D, Berger MF. The effectiveness of a weak opioid medication versus a cyclooxygenase-2 (COX-2) selective non-steroidal anti-inflammatory drug in treating flare-up of chronic low-back pain: results from two randomized, double-blind, 6-week studies. J Int Med Res. 2009;37(6):1789-1802.

13. Chou R, Huffman LH. Medications for acute and chronic low back pain: a review of the evidence for an American pain society/American college of physicians clinical practice guideline. Ann Intern Med. 2007;147(7):505-514.

14. Sloot S, Boland J, Snowden JA, et al. Side effects of analgesia may significantly reduce quality of life in symptomatic multiple myeloma: a crosssectional prevalence study. Support Care Cancer. 2015;23(3):671-678.

15. Oderda GM, Gan TJ, Johnson BH, Robinson SB. Effect of opioid-related adverse events on outcomes in selected surgical patients. J Pain Palliat Care Pharmacother. 2013;27(1):62-70.

16. Kessler ER, Shah M, Gruschkus SK, Raju A. Cost and quality implications of opioid-based postsurgical pain control using administrative claims data from a large health system: opioid-related adverse events and their impact on clinical and economic outcomes. Pharmacotherapy. 2013;33(4):383-391.

17. Medical Expenditure Panel Survey [homepage on the Internet]. Available from: https://meps.ahrq.gov/mepsweb/. Accessed January 4, 2019.

18. Shah D, Anupindi VR, Vaidya V. Pharmacoeconomic analysis of pain medications used to treat adult patients with chronic back pain in the United States. J Pain Palliat Care Pharmacother. 2016;30(4):300-307.

19. Smith M, Monica S. Identifying episodes of back pain using medical expenditures panel survey data: patient experience, use of services, and chronicity. J Manipulative Physiol Ther. 2010;33(8):562-575.

20. Ware J, Kosinski M, Keller SD. A 12-Item Short-Form Health Survey: construction of scales and preliminary tests of reliability and validity. Med Care. 1996;34(3):220-233.

21. Bureau of Labor Statistics [homepage on the Internet]. Available from: https://data.bls.gov/timeseries/CUUR0000SAM?output_ view=pct_12mths. Accessed January 4, 2019.

22. CDC Guideline for Prescribing Opioids for Chronic Pain - United States, 2016. MMWR Recomm Rep. 2016;65(1):1-49.
23. Deyo RA, Smith DH, Johnson ES, et al. Opioids for back pain patients: primary care prescribing patterns and use of services. J Am Board Fam Med. 2011;24(6):717-727.

24. Bawor M, Dennis BB, Varenbut M, et al. Sex differences in substance use, health, and social functioning among opioid users receiving methadone treatment: a multicenter cohort study. Biol Sex Differ. 2015;6:21.

25. Manubay J, Davidson J, Vosburg S, Jones J, Comer S, Sullivan M. Sex differences among opioid-abusing patients with chronic pain in a clinical trial. J Addict Med. 2015;9(1):46-52.

26. Paller CJ, Campbell CM, Edwards RR, Dobs AS. Sex-based differences in pain perception and treatment. Pain Med. 2009;10(2):289-299.

27. Bartley EJ, Fillingim RB. Sex differences in pain: a brief review of clinical and experimental findings. Br J Anaesth. 2013;111(1):52-58.

28. Crook J, Rideout E, Browne G. The prevalence of pain complaints in a general population. Pain. 1984;18(3):299-314.

29. Pitkala KH, Strandberg TE, Tilvis RS. Management of nonmalignant pain in home-dwelling older people: a population-based survey. $\mathrm{J} \mathrm{Am}$ Geriatr Soc. 2002;50(11):1861-1865.

30. Jena AB, Goldman D, Karaca-Mandic P. Hospital prescribing of opioids to medicare beneficiaries. JAMA Intern Med. 2016;176(7):990-997.

31. Chen I, Kurz J, Pasanen M, et al. Racial differences in opioid use for chronic nonmalignant pain. J Gen Intern Med. 2005;20(7):593-598.

32. Davis MA, Lin LA, Liu H, Sites BD. Prescription opioid use among adults with mental health disorders in the United States. J Am Board Fam Med. 2017;30(4):407-417.

33. Eriksen J, Sjøgren P, Bruera E, Ekholm O, Rasmussen NK. Critical issues on opioids in chronic non-cancer pain: an epidemiological study. Pain. 2006;125(1-2):172-179.

34. Sanford D, Thornley P, Teriaky A, Chande N, Gregor J. Opioid use is associated with decreased quality of life in patients with Crohn's disease. Saudi J Gastroenterol. 2014;20(3):182-187.

35. Dillie KS, Fleming MF, Mundt MP, French MT. Quality of life associated with daily opioid therapy in a primary care chronic pain sample. J Am Board Fam Med. 2008;21(2):108-117.

36. Hayes CJ, Payakachat N, Li C. Evaluation of opioid use among patients with back disorders and arthritis. Qual Life Res. 2018;27(11):3021-3035.

37. Davies EC, Green CF, Taylor S, Williamson PR, Mottram DR, Pirmohamed M. Adverse drug reactions in hospital in-patients: a prospective analysis of 3695 patient-episodes. PLoS One. 2009;4(2):e4439.

38. Rasu RS, Vouthy K, Crowl AN, et al. Cost of pain medication to treat adult patients with nonmalignant chronic pain in the United States. J Manag Care Spec Pharm. 2014;20(9):921-928. 


\section{Supplementary materials}

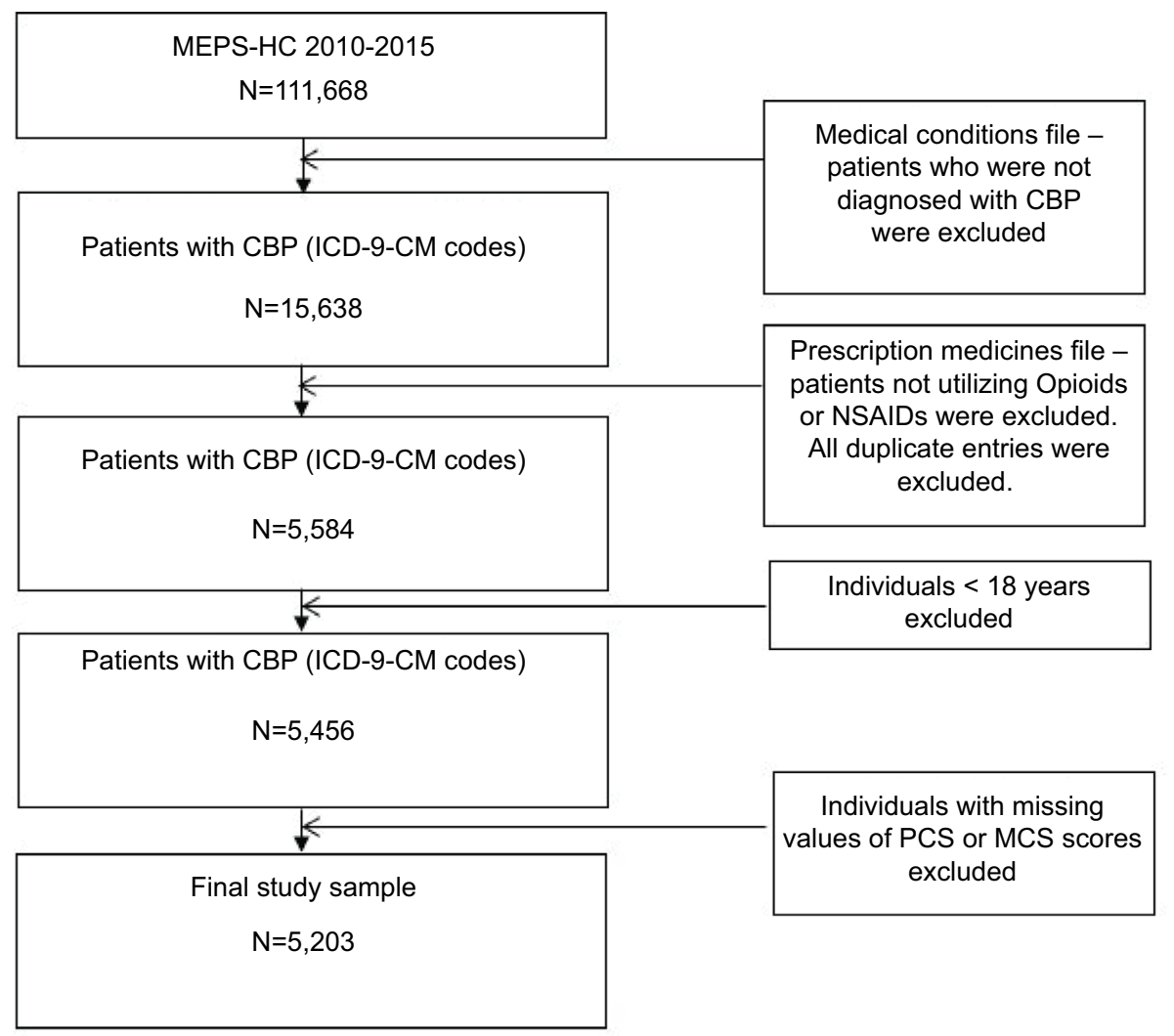

Figure SI Flowchart detailing data extraction and sample selection.

Abbreviations: CBP, chronic back pain; ICD-9-CM, ICD, Ninth Revision, Clinical Modification; MCS, mental component summary; MEPS-HC, Medical Expenditure Panel Survey Household Component; PCS, physical component summary.

Table SI Baseline characteristics of individuals with CBP (MEPS 20I I-20I5)

\begin{tabular}{|c|c|c|c|c|}
\hline \multirow[t]{3}{*}{ Characteristics } & \multicolumn{4}{|l|}{ CBP } \\
\hline & \multicolumn{2}{|c|}{ Unweighted $(\mathrm{N}=5,203)$} & \multicolumn{2}{|c|}{ Weighted $(\mathrm{N}=||, 249,|| 3)$} \\
\hline & $\mathbf{N}$ (\% within group) & $P$-value & $\mathbf{N}$ (\% within group) & $P$-value \\
\hline \multicolumn{5}{|l|}{ Year } \\
\hline 2011 & $795(15.3)$ & $<0.000 \mathrm{I}^{\mathrm{a}}$ & $1,758,446(15.6)$ & $<0.000 I^{2}$ \\
\hline 2012 & $956(18.4)$ & & $1,968,553(17.5)$ & \\
\hline 2013 & $952(18.3)$ & & $2,|20,00|(\mid 8.9)$ & \\
\hline 2014 & $\mathrm{I}, 046(20.1)$ & & $2,175,406(19.3)$ & \\
\hline 2015 & $\mathrm{I}, 454(27.9)$ & & $3,226,707(28.7)$ & \\
\hline \multicolumn{5}{|l|}{ Sex } \\
\hline Male & $2,040(39.2)$ & $<\left.0.000\right|^{a}$ & $4,787,440(42.6)$ & $<0.000 I^{2}$ \\
\hline Female & $3,163(60.8)$ & & $6,46 I, 672(57.4)$ & \\
\hline \multicolumn{5}{|l|}{ Age } \\
\hline $18-39$ years & I,379 (26.5) & $<0.0001^{a}$ & $2,7 \mid 6,928(24 . I)$ & $<0.00 I^{a}$ \\
\hline 40-64 years & $2,678(5 I .5)$ & & $5,722,438(50.9)$ & \\
\hline$\geq 65$ & $\mathrm{I}, \mathrm{I} 46(22.0)$ & & $2,809,747(25.0)$ & \\
\hline \multicolumn{5}{|l|}{ Race } \\
\hline White & 3,707 (7I.3) & $<\left.0.000\right|^{a}$ & $9,317,125(82.8)$ & $<0.000 I^{a}$ \\
\hline African American & $\mathrm{I}, 088(20.9)$ & & $\mathrm{I}, 257,54 \mathrm{I}(\mathrm{II} .2)$ & \\
\hline Others & $408(7.8)$ & & $674,447(6.0)$ & \\
\hline
\end{tabular}


Table SI (Continued)

\begin{tabular}{|c|c|c|c|c|}
\hline \multirow[t]{3}{*}{ Characteristics } & \multicolumn{4}{|l|}{ CBP } \\
\hline & \multicolumn{2}{|c|}{ Unweighted $(\mathrm{N}=5,203)$} & \multicolumn{2}{|c|}{ Weighted $(\mathrm{N}=||, 249,|| 3)$} \\
\hline & $\mathbf{N}$ (\% within group) & $P$-value & $\mathbf{N}$ (\% within group) & $P$-value \\
\hline \multicolumn{5}{|l|}{ Marital status } \\
\hline Married & $2,534(48.7)$ & $<0.000 I^{\mathrm{a}}$ & $6,186,508(55.0)$ & $<0.000 I^{a}$ \\
\hline Previously married & $1,579(30.3)$ & & $3,105,396(27.6)$ & \\
\hline Never married & $1,090(21.0)$ & & $1,957,209(17.4)$ & \\
\hline \multicolumn{5}{|l|}{ Region } \\
\hline Northeast & $815(15.7)$ & $<0.000 I^{\mathrm{a}}$ & $1,798,103(16.0)$ & $<0.00 I^{a}$ \\
\hline Midwest & $\mathrm{I}, \mathrm{I} 67(22.4)$ & & $2,761,900(24.5)$ & \\
\hline South & $\mathrm{I}, 886(36.2)$ & & $4,036,862(35.9)$ & \\
\hline West & $1,335(25.7)$ & & $2,652,248(23.6)$ & \\
\hline \multicolumn{5}{|l|}{ Poverty status } \\
\hline Poor & $2,470(47.5)$ & $<0.000 \mathrm{I}^{\mathrm{a}}$ & $4,080,374(36.3)$ & $<0.000 I^{a}$ \\
\hline Middle income & $\mathrm{I}, 388(26.7)$ & & $3,094,877(27.5)$ & \\
\hline High income & $1,345(25.8)$ & & $4,073,862(36.2)$ & \\
\hline \multicolumn{5}{|l|}{ Education level } \\
\hline $0-12$ years & $\mathrm{I}, 066(20.5)$ & $<0.000 I^{\mathrm{a}}$ & $1,578,162(14.0)$ & $<0.000 \mathrm{I}^{\mathrm{a}}$ \\
\hline$>12$ years & $4,137(79.5)$ & & $9,670,950(86.0)$ & \\
\hline \multicolumn{5}{|c|}{ Health insurance status } \\
\hline Public & $2,854(54.9)$ & $<0.000 I^{a}$ & $7,258,554(64.5)$ & $<0.000 I^{a}$ \\
\hline Private & $\mathrm{I}, 854(35.6)$ & & $3,190,728(28.4)$ & \\
\hline Uninsured & $495(9.5)$ & & $799,830(7.1)$ & \\
\hline \multicolumn{5}{|c|}{ Comorbidities $(\mathrm{CCl})^{b}$} \\
\hline 0 & $2,893(55.6)$ & $<0.000 \mathrm{I}^{\mathrm{a}}$ & $6,201,959(55.1)$ & $<0.000 \mathrm{I}^{\mathrm{a}}$ \\
\hline$I-2$ & $\mathrm{I}, 566(30.1)$ & & $3,396,897$ (30.2) & \\
\hline $3-4$ & 577 (II.I) & & I,256,245 (II I.2) & \\
\hline$>4$ & $167(3.2)$ & & $394,012(3.5)$ & \\
\hline
\end{tabular}

Notes: aSignificant at $P<0.05$. ${ }^{b}$ Comorbidities were estimated using the $\mathrm{CCl}$.

Abbreviations: CBP, chronic back pain; $\mathrm{CCl}$, Charlson Comorbidity Index; MEPS, Medical Expenditure Panel Survey.

Table S2 Differences in health care utilization individuals utilizing opioids only, NSAIDs only and a combination of NSAIDs and opioids

\begin{tabular}{|l|l|l|l|l|}
\hline Health care utilization & Opioids only & NSAIDs only & $\begin{array}{l}\text { Opioids and NSAIDs } \\
\text { (combination) }\end{array}$ & P-value \\
\cline { 2 - 5 } & $\begin{array}{l}\text { Mean no. of visits } \\
\text { per individual }\end{array}$ & $\begin{array}{l}\text { Mean no. of visits } \\
\text { per individual }\end{array}$ & $\begin{array}{l}\text { Mean no. of visits } \\
\text { per individual }\end{array}$ \\
\hline No. of inpatient visits & 0.29 & 0.09 & 0.28 & $<0.000 \mathrm{I}^{\mathrm{a}}$ \\
\hline No. of outpatient visits & 1.39 & 0.80 & 1.43 & $<0.000 \mathrm{I}^{\mathrm{a}}$ \\
\hline No. of office-based visits & 14.46 & 10.18 & 14.98 & $<0.000 \mathrm{I}^{\mathrm{a}}$ \\
\hline No. of ER visits & 0.60 & 0.38 & 0.86 & $<0.000 \mathrm{I}^{\mathrm{a}}$ \\
\hline
\end{tabular}

Note: asignificant at $P<0.05$.

Abbreviation: ER, emergency room.

Table S3 Generalized linear models: incremental effects of total health care expenditures among US adults diagnosed with CBP accounting for relevant covariates (adjusted to 2017 dollars)

\begin{tabular}{|l|l|l|l|l|}
\hline Characteristics & Incremental cost & 95\% Cl & P-value \\
\hline Year & & & & \\
\hline 2011 & 0 (reference) & & & \\
\hline 2012 & $-1,555$ & $-3,494$ & 383 & \\
\hline 2013 & $-1,176$ & $-3,119$ & 766 & 0.11 \\
\hline 2014 & 973 & $-3,306$ & 508 & 0.23 \\
\hline 2015 & 914 & $-2,003$ & 1,579 & 0.15 \\
\hline
\end{tabular}

(Continued) 
Table S3 (Continued)

\begin{tabular}{|c|c|c|c|c|}
\hline \multirow{2}{*}{$\begin{array}{l}\text { Characteristics } \\
\text { Group }\end{array}$} & \multirow[t]{2}{*}{ Incremental cost } & \multicolumn{2}{|l|}{$95 \% \mathrm{Cl}$} & \multirow[t]{2}{*}{$P$-value } \\
\hline & & & & \\
\hline Opioids only & 0 (reference) & & & \\
\hline NSAIDs only & $-5,362$ & $-6,711$ & $-4,013$ & $<0.000 \mathrm{I}^{\mathrm{a}}$ \\
\hline Opioids and NSAIDs & -210 & $-1,642$ & 1,220 & 0.77 \\
\hline \multicolumn{5}{|l|}{ Sex } \\
\hline Male & 0 (reference) & & & \\
\hline Female & $\mathrm{I}, 304$ & 124 & 2,484 & $0.03^{\mathrm{a}}$ \\
\hline \multicolumn{5}{|l|}{ Age } \\
\hline $18-39$ years & 0 (reference) & & & \\
\hline 40-64 years & 1,228 & -239 & 2,696 & 0.10 \\
\hline$\geq 65$ & 2,192 & 320 & 4,064 & $0.02^{\mathrm{a}}$ \\
\hline \multicolumn{5}{|l|}{ Race } \\
\hline White & 0 (reference) & & & \\
\hline African American & $-1,576$ & $-3,043$ & -109 & $0.03^{\mathrm{a}}$ \\
\hline Others & $-2,967$ & $-5,091$ & -843 & $0.0 \mathrm{I}^{\mathrm{a}}$ \\
\hline \multicolumn{5}{|l|}{ Marital status } \\
\hline Married & 0 (reference) & & & \\
\hline Previously married & 861 & -540 & 2,263 & 0.23 \\
\hline Never married & 1,245 & $-1,597$ & 1,622 & 0.10 \\
\hline \multicolumn{5}{|l|}{ Region } \\
\hline Northeast & 0 (reference) & & & \\
\hline Midwest & $-1,034$ & $-2,895$ & 827 & 0.28 \\
\hline South & -905 & $-2,632$ & 820 & 0.30 \\
\hline West & -970 & $-2,788$ & 847 & 0.29 \\
\hline \multicolumn{5}{|l|}{ Poverty status } \\
\hline Poor & 0 (reference) & & & \\
\hline Middle income & 414 & $-1,090$ & 1,918 & 0.59 \\
\hline High income & $\mathrm{I}, 83 \mathrm{I}$ & 162 & 3,500 & $0.03^{\mathrm{a}}$ \\
\hline \multicolumn{5}{|l|}{ Education } \\
\hline $0-12$ years & 0 (reference) & & & \\
\hline$>12$ years & $\mathrm{I}, \mathrm{I} 45$ & -339 & 2,630 & 0.13 \\
\hline \multicolumn{5}{|l|}{ Health insurance } \\
\hline Public & 0 (reference) & & & \\
\hline Private & $-2,850$ & $-4,325$ & $-1,374$ & $0.00^{\mathrm{a}}$ \\
\hline Uninsured & $-4,449$ & $-6,551$ & $-2,347$ & $<0.000 \mathrm{I}^{\mathrm{a}}$ \\
\hline \multicolumn{5}{|l|}{ Comorbidity $(\mathrm{CCl})^{\mathrm{b}}$} \\
\hline 0 & 0 (reference) & & & \\
\hline $\mathrm{I}-2$ & 3,835 & 2,514 & 5,157 & $<0.000 \mathrm{I}^{\mathrm{a}}$ \\
\hline $3-4$ & 7,097 & 5,161 & 9,033 & $<0.000 \mathrm{I}^{\mathrm{a}}$ \\
\hline$>4$ & 16,753 & 13,473 & 20,033 & $<0.000 I^{a}$ \\
\hline
\end{tabular}

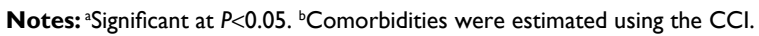

Abbreviations: $\mathrm{CBP}$, chronic back pain; $\mathrm{CCl}$, Charlson Comorbidity Index.

Journal of Pain Research

\section{Publish your work in this journal}

The Journal of Pain Research is an international, peer reviewed, open access, online journal that welcomes laboratory and clinical findings in the fields of pain research and the prevention and management of pain. Original research, reviews, symposium reports, hypothesis formation and commentaries are all considered for publication.
The manuscript management system is completely online and includes a very quick and fair peer-review system, which is all easy to use. Visit http://www.dovepress.com/testimonials.php to read real quotes from published authors. 